Article

\title{
Rational Design of an Ion-Imprinted Polymer for Aqueous Methylmercury Sorption
}

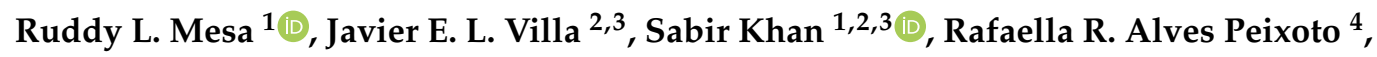 \\ Marcelo A. Morgano ${ }^{5}\left(\mathbb{D}\right.$, Luís Moreira Gonçalves ${ }^{6}(\mathbb{D}$, Maria D. P. T. Sotomayor $2,3, *(\mathbb{D})$ \\ and Gino Picasso ${ }^{1, *}$ \\ 1 Laboratory of Physical Chemistry Research, Faculty of Sciences, National University of Engineering, \\ Lima 15333, Peru; a20156475@pucp.edu.pe (R.L.M.M.); sabir_chemist@yahoo.com (S.K.) \\ 2 Institute of Chemistry, State University of São Paulo (UNESP), Araraquara, SP 14800-060, Brazil; \\ villa.javier03@gmail.com \\ 3 National Institute for Alternative Technologies of Detection, Toxicological Evaluation and Removal of \\ Micropollutants and Radioactives (INCT-DATREM), Araraquara, SP 14800-060, Brazil \\ 4 Department of Analytical Chemistry, Fluminense Federal University (UFF), Niterói, RJ 24020-150, Brazil; \\ rafaellapeixoto@id.uff.br \\ 5 Institute of Food Technology (ITAL), Campinas, SP 13070-178, Brazil; morgano.ital@gmail.com \\ 6 Institute of Chemistry, University of São Paulo (USP), São Paulo, SP 05508-000, Brazil; lmgoncalves@iq.usp.br \\ * Correspondence: m.sotomayor@unesp.br (M.D.P.T.S.); gpicasso@uni.edu.pe (G.P.); \\ Tel.: +55-16-33019620 (M.D.P.T.S.)
}

Received: 28 October 2020; Accepted: 23 November 2020; Published: 17 December 2020

check for updates

\begin{abstract}
Methylmercury $\left(\mathrm{MeHg}^{+}\right)$is a mercury species that is very toxic for humans, and its monitoring and sorption from environmental samples of water are a public health concern. In this work, a combination of theory and experiment was used to rationally synthesize an ion-imprinted polymer (IIP) with the aim of the extraction of $\mathrm{MeHg}^{+}$from samples of water. Interactions among $\mathrm{MeHg}^{+}$ and possible reaction components in the pre-polymerization stage were studied by computational simulation using density functional theory. Accordingly, 2-mercaptobenzimidazole (MBI) and 2-mercaptobenzothiazole (MBT), acrylic acid (AA) and ethanol were predicted as excellent sulfhydryl ligands, a functional monomer and porogenic solvent, respectively. Characterization studies by scanning electron microscopy (SEM) and Brunauer-Emmett-Teller (BET) revealed the obtention of porous materials with specific surface areas of $11 \mathrm{~m}^{2} \mathrm{~g}^{-1}$ (IIP-MBI-AA) and $5.3 \mathrm{~m}^{2} \mathrm{~g}^{-1}$ (IIP-MBT-AA). Under optimized conditions, the maximum adsorption capacities were $157 \mu \mathrm{g} \mathrm{g}^{-1}$ (for IIP-MBI-AA) and $457 \mu \mathrm{g} \mathrm{g}^{-1}$ (for IIP-MBT-AA). The IIP-MBT-AA was selected for further experiments and application, and the selectivity coefficients were $\mathrm{MeHg}^{+} / \mathrm{Hg}^{2+}(0.86), \mathrm{MeHg}^{+} / \mathrm{Cd}^{2+}(260), \mathrm{MeHg}^{+} / \mathrm{Pb}^{2+}$ (288) and $\mathrm{MeHg}^{+} / \mathrm{Zn}^{2+}$ (1510), highlighting the material's high affinity for $\mathrm{MeHg}^{+}$. The IIP was successfully applied to the sorption of $\mathrm{MeHg}^{+}$in river and tap water samples at environmentally relevant concentrations.
\end{abstract}

Keywords: bulk polymerization; computational modelling; environmental analysis; imprinting technology; mercury detection and removal; ion recognition; ionic imprinting polymers; sample preparation; separation science; water analysis

\section{Introduction}

Methylmercury $\left(\mathrm{MeHg}^{+}\right)$is one of the mercury chemical forms of highest toxicity for humans among mercury compounds [1]. Once in the human body, $\mathrm{MeHg}^{+}$presents a high affinity to the sulfhydryl group present in proteins. This interaction can induce changes in the protein structures and a consequent loss of their functions [2]. The deleterious effects are more severe for fetuses; $\mathrm{MeHg}^{+}$ 
exposure can seriously impair neurological development [3]. In addition, $\mathrm{MeHg}^{+}$is bioaccumulated and biomagnified in the marine food chain, as this specie is found in almost all marine species as a result of methylation of inorganic mercury by microorganisms present in sediments and aquatic organisms [4]. In natural water, reports estimated that $\mathrm{MeHg}^{+}$percentage varied from 0.27 to $20 \%$ in relation to total mercury [5,6]. In this way, the consumption of contaminated water and seafood is the main source of non-occupational exposure to $\mathrm{MeHg}^{+}$. For these reasons, the development of analytical strategies with the aim of $\mathrm{MeHg}^{+}$determination/removal is a question of public health concern. Although several methods have been proposed for the determination and removal of $\mathrm{MeHg}^{+}$ in various samples [7-13], the synthesis and application of highly selective materials for efficient determination/removal of $\mathrm{MeHg}^{+}$is a topic that deserves further attention.

Imprinted polymers are materials with the capacity to selectively capture molecules or metal ions and have become very popular sorbents for a wide variety of applications [14-16]. Particularly, ion-imprinted polymers (IIPs) are sorbents designed for targeting metal ions and have been recently used as solid phase extraction materials, sensors and separating membranes [17-22]. In the synthesis of IIPs, ligands containing electron-rich heteroatoms, such as nitrogen, phosphorus, sulfur and oxygen, are normally used to promote the formation of chelate with the targeted metal [23]. This three-step synthesis normally involves: (1) formation of a pre-polymerization complex with interaction of the metal ion, ligand and functional monomer (FM); (2) polymerization of the complex monomer with the addition of a cross-linker and initiator; (3) removal of the template to produce the imprinted polymer [24]. After proper removal of the metal ions from the bulk, specific cavities/binding sites able to selectively recognize the metal are generated [25].

IIPs for $\mathrm{MeHg}^{+}$commonly require a trapping technique using a pre-polymerization mixture based on a ternary template/ligand/FM. The template is normally the analyte, using methylmercury chloride $(\mathrm{MeHgCl})$ [26-30] as the ion source, although $\mathrm{MeHgCl}$ is a hardly soluble salt. Ligands containing sulfhydryl groups are the more suitable ligands since mercury ions have a specific affinity to sulfur, even though ligands containing $\mathrm{N}$-based functional groups have been found to interact with $\mathrm{MeHg}^{+}$[24]. 1-pyrrolidinecarbodithioic acid [26-28], phenobarbital [29-31] and methacrylic acid [26-31] have been reported in the synthesis of $\mathrm{MeHg}^{+}$IIPs such as sulfhydryl ligand, $\mathrm{N}$-based ligand and FM, respectively. In the present study, sulfhydryl ligands (2-mercaptobenzimidazole and 2-mercaptobenzothiazole) are tested for first time in $\mathrm{MeHg}^{+}$IIP synthesis.

Computational simulation allows the evaluation of several components for IIP synthesis and their interaction; it is assumed that the formed complexes preserve their chemical structures after polymerization, thus, only the pre-polymerization system is modeled [32,33]. Therefore, the consideration of individual interactions among template, ligand, FM, cross-linker and solvent might significantly reduce the time and resources to choose the components for IIP synthesis. Density functional theory (DFT) methods are typically used to calculate the "binding energy" for polymer components selection [34,35].

In this work, theoretical calculations were used to predict relevant experimental conditions in the synthesis of an IIP for aqueous $\mathrm{MeHg}^{+}$sorption. DFT was used for geometry optimization and binding energy calculations in systems containing $\mathrm{MeHg}^{+}$, sulfhydryl ligands, FM and solvent. For the validation of the theoretical results, IIPs and non-imprinted polymers (NIPs) were synthesized by bulk polymerization and characterized by Fourier transform infrared spectroscopy (FTIR), scanning electron microscopy (SEM), thermogravimetric analysis (TGA) and Brunauer-Emmett-Teller (BET) measurements. The sorption and selectivity study were performed to assess the efficiency of the proposed $\mathrm{MeHg}^{+}-\mathrm{IIP}$ and for comparison with the corresponding NIPs. Finally, the $\mathrm{MeHg}^{+}-\mathrm{IIP}$ was successfully applied to the quantitative sorption of $\mathrm{MeHg}^{+}$in samples in river and tap water at environmentally relevant concentrations. 


\section{Materials and Methods}

\subsection{Reagents and Samples}

$\mathrm{MeHgCl}$, tiourea, 2-mercaptobenzimidazole (MBI), 2-mercaptobenzothiazole (MBT), acrylic acid (AA), ethylene glycol dimethacrylate (EGDMA) and azodiisobutyronitrile (AIBN) were purchased from Sigma-Aldrich (St. Louis, MO, USA); ethanol (EtOH) absolute (99.9\%) was obtained from JT Baker (Radnor, PA, USA); $\mathrm{MeHgCl}$ standard solution $1000 \mathrm{mg} \mathrm{L}^{-1}$ from Alfa Aesar (Tewksbury, MA, USA); and hydrochloric acid $(\mathrm{HCl})$, sodium acetate $\left(\mathrm{NaCH}_{3} \mathrm{COO}\right)$, acetic acid $\left(\mathrm{CH}_{3} \mathrm{COOH}\right)$, sodium hydrogen phosphate $\left(\mathrm{Na}_{2} \mathrm{HPO}_{4}\right)$, sodium dihydrogen phosphate $\left(\mathrm{NaH}_{2} \mathrm{PO}_{4}\right)$, sodium hydroxide $(\mathrm{NaOH})$, and sodium tetraborate $\left(\mathrm{Na}_{2} \mathrm{~B}_{4} \mathrm{O}_{7}\right)$ were purchased from Merck (Darmstadt, Germany);. For the selectivity study, solutions were prepared from salt standards of lead nitrate, cadmium nitrate tetrahydrate, zinc sulfate monohydrate, and mercury dichloride (all acquired form Sigma-Aldrich). All the reagents used in this work were of analytical grade, and the solutions were prepared in ultrapure water (resistivity of $18.2 \mathrm{M} \Omega \mathrm{cm}$ ).

The samples were collected from the Batalha river $(21.72 \mathrm{~S}, 49.20 \mathrm{~W})$, and directly from the tap.

WARNING: $\mathrm{MeHgCl}$ appears as white microcrystals and is very toxic by inhalation, in contact with skin and if swallowed. Protection measures such as glasses, full face-shields, gloves and particulate respirators are required to manipulate it. Its disposal should also be carried out carefully.

\subsection{Density Functional Method}

DFT is a computational method applied to electronic systems to obtain the energy and the electronic distribution of the fundamental state, which is a simpler magnitude than the wave function and therefore simplifies the study of complex systems [33,34]. Accordingly, the binding energies were calculated using Gibbs free energies $(\Delta G)$, which is a compressive parameter (involving enthalpy, entropy and temperature) and a determinant thermodynamic criterion for a spontaneous process [32]. The computational simulations were performed using a Gaussian 09 package [36], M06-2X level of theory [37] and basis set 6-31G(d) [38,39] for the carbon, sulfur, nitrogen, oxygen and hydrogen atoms. In the case of $\mathrm{MeHg}^{+}$, a pseudopotential (LANL2DZ) [40] was employed to describe the core orbitals of the mercury atom.

\subsection{Ion-Imprinted Polymer (IIP) Synthesis}

$\mathrm{MeHg}^{+}-\mathrm{IIPs}$ were synthetized via bulk polymerization using $\mathrm{MeHgCl}(0.5 \mathrm{mmol})$ as the template; MBI (0.5 mmol) or MBT (0.5 mmol) as ligands for comparison; AA (1.0 mmol) as FM; EGDMA (2 mmol) as a cross-linker, $\mathrm{AIBN}(0.5 \mathrm{mmol})$ as radical initiator; $\mathrm{EtOH}$ as solvent $(20 \mathrm{~mL})$. First, the template and ligand were dissolved in $\mathrm{EtOH}$, the $\mathrm{FM}$ was added, and the mixture was kept under vigorous stirring for $2 \mathrm{~h}$. Subsequently, the cross-linker and the radical initiator were added under nitrogen atmosphere. Then, the glass tube was sealed under an inert environment, and the temperature was set to $65^{\circ} \mathrm{C}$ to initiate the polymerization. A schematic illustration of the IIP synthesis is shown in Figure 1.

A

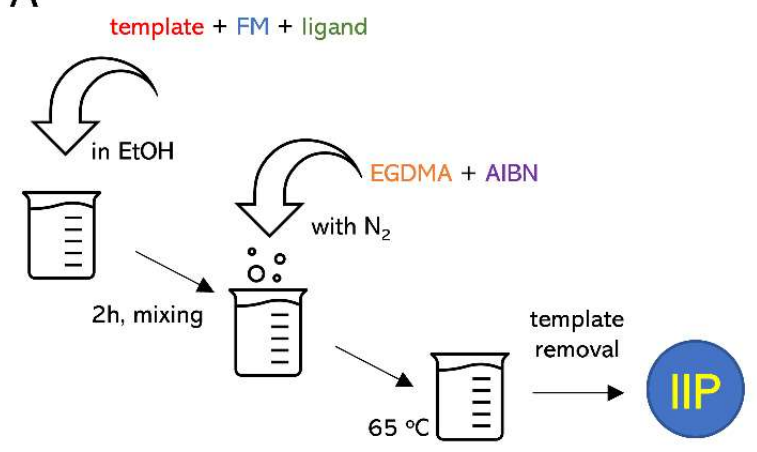

B

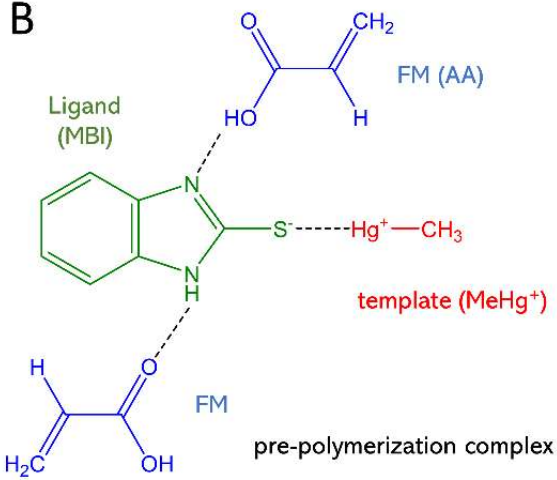

Figure 1. Schematic illustration of the synthesis of ion-imprinted polymers (IIPs) (A); pre-polymerization complex with the 2-mercaptobenzimidazole (MBI) ligand (B). 
The template ion $\mathrm{MeHg}^{+}$in the IIPs was removed with a mixture of tiourea $2.5 \%$ w/v and $\mathrm{HCl} 1 \mathrm{~mol} \mathrm{~L}^{-1}$ solution until mercury could no longer be detected in the solution by thermal decomposition amalgamation atomic absorption spectrometry (TDA-AAS), following a previously proposed method [10]. The polymer was dried at $60{ }^{\circ} \mathrm{C}$ and stored at room temperature. Two non-imprinted polymers (NIPs) were synthesized following the same procedure, but no template was added in one of them, and neither template nor ligand was added in the other. Thus, the synthesized materials were IIP-MBI-AA and IIP-MBT-AA ( $\mathrm{CH}_{3} \mathrm{Hg}^{+}$imprinted polymers), NIP-MBI-AA and NIP-MBT-AA (non-imprinted polymers with ligand) and NIP-AA (non-imprinted polymers without ligand).

\subsection{Polymer Characterization}

Characterizations of the $\mathrm{MeHg}^{+}-$IIPs and NIPs were carried out by attenuated total reflection (ATR)-FTIR in a Bruker spectrometer (Billerica, MA, USA) Alpha II in the range of 4000-400 $\mathrm{cm}^{-1}$ to identify functional groups in each material. Morphology was examined by scanning electron microscopy (SEM) of the JEOL brand model JSM7500F (Tokyo, Japan). The samples were dried at $60{ }^{\circ} \mathrm{C}$, placed on a carbon wafer and then subjected to a sputtering using a spray coating equipment of the Bal Tec brand model SCD 050. The nitrogen adsorption/desorption analysis was used to evaluate the surface area by the BET method (Brunauer-Emmett-Teller), whereas the total volume and pore diameter was evaluated by the BJH method (Barret-Joyner-Halenda) using a Micromeritics Gemini VII-2390 (Norcross, GA, USA). The samples were pretreated in a vacuum by degassing at $100{ }^{\circ} \mathrm{C}$ for $2 \mathrm{~h}$. The thermogravimetric analysis (TGA) and differential thermal analysis (DTA) were applied to evaluate the thermal stability of the materials. Instrument Perkin Elmer STA 6000 (Waltham, MA, USA) was used to obtain the thermograms. The thermograms were obtained using $5 \mathrm{mg}$ of mass of the sample and a heating ramp of $10{ }^{\circ} \mathrm{C} \mathrm{min}-1$ in the range of from 35 to $800{ }^{\circ} \mathrm{C}$ in nitrogen atmosphere with a flow rate of $20 \mathrm{~mL} \mathrm{~min}^{-1}$ using a Perkin Elmer STA 6000 instrument.

\subsection{Sorption Studies}

Sorption experiments of $\mathrm{MeHg}^{+}$from aqueous solutions were carried out by TDA-AAS, using a direct mercury analyzer (DMA) for the determination of total mercury [10]. Sorption isotherms were studied at different $\mathrm{MeHg}^{+}$concentrations $\left(25,50,100,150,200,300,400,600\right.$ and $\left.800 \mathrm{mg} \mathrm{L}^{-1}\right)$. Polymer concentration was kept constant at $3 \mathrm{mg}$ of polymeric material in $2 \mathrm{~mL}$ of $\mathrm{MeHg}^{+}$solution and shaken for $2 \mathrm{~h}$. Then, the polymers were separated by centrifugation for $10 \mathrm{~min}$ at $450 \mathrm{RCF}$. After that, the concentration of $\mathrm{MeHg}^{+}$was quantified in the supernatant using TDA-AAS. The effect of $\mathrm{pH}$ on $\mathrm{MeHg}^{+}$sorption was also studied with the following buffer solutions: $\mathrm{HCl}$ for $\mathrm{pH} 2.0$; $\mathrm{NaCH}_{3} \mathrm{COO} / \mathrm{CH}_{3} \mathrm{COOH}$ for $\mathrm{pH} 4.0-6.0$; $\mathrm{Na}_{2} \mathrm{HPO}_{4} / \mathrm{NaH}_{2} \mathrm{PO}_{4}$ for $\mathrm{pH} 7.0-8.0 ; \mathrm{Na}_{2} \mathrm{~B}_{4} \mathrm{O}_{7} / \mathrm{NaOH}$ for $\mathrm{pH} 10$.

The sorption kinetic was studied in the range of 5-300 min. Afterwards, the samples were centrifuged for $10 \mathrm{~min}$ at $450 \mathrm{RCF}$, and the residual solution was analyzed by TDA-AAS. The other parameters were kept constant $\left(100 \mu \mathrm{g} \mathrm{L} \mathrm{LeHg}^{+}\right.$solution, $\mathrm{pH} 8$ with $\mathrm{Na}_{2} \mathrm{HPO}_{4} / \mathrm{NaH}_{2} \mathrm{PO}_{4}$ buffer, polymer concentration: $3 \mathrm{mg}$ of polymeric material in $2 \mathrm{~mL} \mathrm{MeHg}^{+}$solutions, and $2 \mathrm{~h}$ of stirring time).

\subsection{Selectivity Studies and Water Analysis}

The selectivity of the synthesized polymer for $\mathrm{MeHg}^{+}$was assessed in binary mixtures of $\mathrm{MeHg}^{+} / \mathrm{Hg}^{2+}, \mathrm{MeHg}^{+} / \mathrm{Cd}^{2+}, \mathrm{MeHg}^{+} / \mathrm{Pb}^{2+}$ and $\mathrm{MeHg}^{+} / \mathrm{Zn}^{2+}$. A polymer mass of $3 \mathrm{mg}$ and $2 \mathrm{~mL}$ standard $\mathrm{MeHg}^{+}$solutions at $\mathrm{pH} 8$ were used for these experiments under shaking for $2 \mathrm{~h}$. The mixture was centrifuged for $10 \mathrm{~min}$ at $450 \mathrm{RCF}$, and the concentration of metal ions was quantified using inductively coupled plasma with optical emission spectrometry (ICP-OES; Optima 3300 DV from Perkin Elmer). The same procedure was used to analyze the water samples. To evaluate the application of the materials, the two water samples were analyzed with the same procedure. These were filtered using Whatman \#42 paper and tested by spiking and recovery experiments. The $\mathrm{MeHg}^{+}$in the IIP was removed with a mixture of tiourea, $2.5 \% \mathrm{w} / \mathrm{v}$, and $1 \mathrm{~mol} \mathrm{~L}^{-1}$ of $\mathrm{HCl}$ following a previously proposed methodology [27], and it was then quantified by TDA-AAS [10]. 


\section{Results and Discussion}

\subsection{Theoretical Selection of the Functional Monomer and Solvent}

A methodology based on the geometry optimization was employed to obtain the lowest energy conformation followed by the calculation of the binding energy $\left(\Delta E_{1}\right)$ of each metal ion-ligand complex. This process was also carried out for the metal ion-ligand-FM complex $\left(\Delta E_{2}\right)$. The interaction energies of complexes were based on the following equations (where $n$ is number of FM for metal ion-ligand-FM complex calculations):

$$
\begin{gathered}
\Delta E_{1}=E(\text { metal ion }- \text { ligand })-E(\text { metal ion })-E(\text { ligand }), \\
\Delta E_{2}=E(\text { metal ion }- \text { ligand }-F M)-E(\text { metal ion }- \text { ligand })-n E(F M),
\end{gathered}
$$

The assessment of these energies in different solvents (water, EtOH, dimethyl sulfoxide (DMSO), dimethylformamide (DMF) and acetonitrile) was also carried out aiming to predict the most stable complex.

The geometry optimization was performed for $\mathrm{MeHg}^{+}$complexes with the sulfhydryl ligands 2-mercaptobenzimidazole (MBI) and 2-mercaptobenzothiazole (MBT). As the linear coordination is the most likely geometry for $\mathrm{MeHg}^{+}$complexes [41], the formation of linear complexes of $\mathrm{MeHg}^{+}-\mathrm{MBI}$ and $\mathrm{MeHg}^{+}-\mathrm{MBT}$ was considered in the geometry optimization in EtOH medium (see Figure 2). For theoretical calculations, the Hg-S distances were calculated to be $2.717 \AA$ and $2.698 \AA$ for $\mathrm{MeHg}^{+}-\mathrm{MBT}$ and $\mathrm{MeHg}^{+}-\mathrm{MBI}$, respectively, which were similar to the experimental values previously reported [42]. Some additional theoretical and experimental bond lengths for these complexes can be found in Table S1.

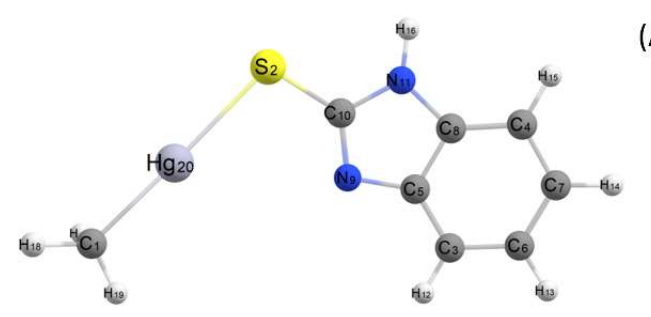

(A)

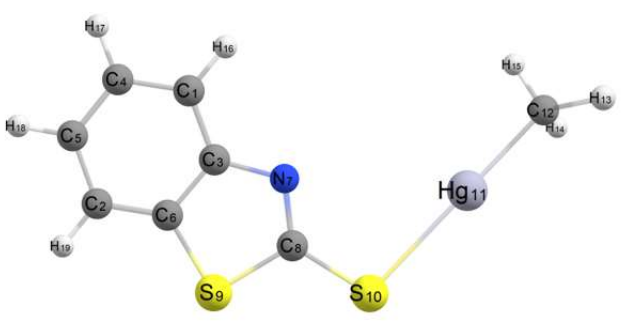

(B)

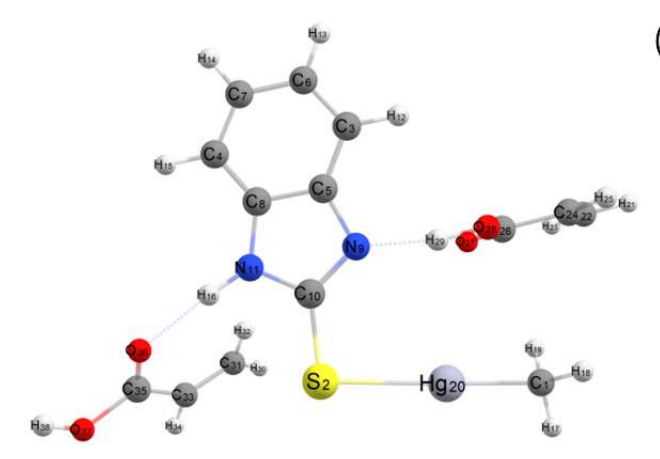

(C)

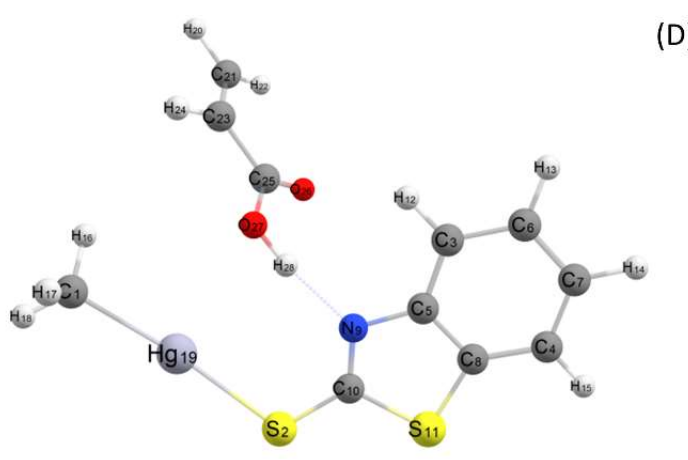

(D)

Figure 2. Geometry optimization of methylmercury $\left(\mathrm{MeHg}^{+}\right)-\mathrm{MBI}(\mathrm{A})$ and $\mathrm{MeHg}^{+}-2$ - mercaptobenzothiazole (MBT) (B) in ethanol (EtOH), and optimized geometries of the pre-polymerization step of $\mathrm{MeHg}^{+}-\mathrm{MBI}(\mathrm{C})$ and $\mathrm{MeHg}^{+}-\mathrm{MBT}$ (D) complexes with acrylic acid (AA) as the functional monomer (FM).

The effect of the solvent on the optimized geometries was also considered, and the binding energies for the $\mathrm{MeHg}^{+}$complexes are presented in Table 1. The results display negative value of $\Delta E$, which indicates spontaneous complex formation and an effective interaction between the $\mathrm{Hg}$ atom and sulfhydryl groups. The most stable (lowest) values obtained were $-15.4 \mathrm{kcal} \mathrm{mol}^{-1}$ for $\mathrm{MeHg}^{+}-\mathrm{MBI}$ and $-12 \mathrm{kcal} \mathrm{mol}^{-1}$ for $\mathrm{MeHg}^{+}-\mathrm{MBT}$ in $\mathrm{EtOH}$, and it was therefore selected as the porogenic solvent. 
Table 1. Solvent effect on binding energy in $\mathrm{MeHg}^{+}$complexes. The dielectric constant values for water, EtOH, dimethyl sulfoxide (DMSO), dimethylformamide (DMF) and acetonitrile were 78.4, 24, 47, 36.7 and 36.5 , respectively.

\begin{tabular}{lcccccc}
\hline \multirow{2}{*}{ Complex } & \multicolumn{7}{c}{ Binding Energy/kcal mol $\mathbf{- 1}^{-1}$} \\
\cline { 2 - 7 } & Water & EtOH & DMSO & DMF & Acetonitrile & Vacuum \\
\hline $\mathrm{MeHg}^{+}-\mathrm{MBI}$ & -10.5 & -15.4 & -12.2 & -13.1 & -13.3 & -168.5 \\
$\mathrm{MeHg}^{+}-\mathrm{MBT}$ & -7.8 & -12.0 & -9.2 & -10.0 & -10.2 & -161.5 \\
\hline
\end{tabular}

Regarding the FM, it should possess higher binding energy toward the ligand than the binding energy with the template to allow for the template/analyte to be adsorbed and desorbed from the IIP bulk. Figure 2 and Table S2 show the chemical structures and the $\Delta E$ of the pre-polymerization stage in the $\mathrm{EtOH}$ solvent. These results show that AA provides stronger IIPs than basic and neutral monomers. $\mathrm{MeHg}^{+}$interacts with MBI $\left(-13.3 \mathrm{kcal} \mathrm{mol}^{-1}\right)$ and MBT $\left(-11 \mathrm{kcal} \mathrm{mol}^{-1}\right)$ by coordinate bonds (1:1), and AA interacts with MBI $\left(-20 \mathrm{kcal} \mathrm{mol}^{-1}\right)$ and MBT $\left(-12.2 \mathrm{kcal} \mathrm{mol}^{-1}\right)$ by hydrogen bonds. Thus, after the theoretical selection of two potentially efficient ligands (MBI and MBT), the FM (AA) and solvent $(\mathrm{EtOH})$, these results were experimentally validated by synthesizing and comparing of the performances of the IIP-MBI-AA and IIP-MBT-AA materials.

\subsection{Characterization of the Synthesized Polymers}

Figure S1 shows the comparison of the FTIR spectra of all the synthesized polymers, which presented similar spectral profiles. IIPs and NIPs showed characteristic peaks of $\mathrm{C}=\mathrm{O}$ stretch $\left(1724 \mathrm{~cm}^{-1}\right), \mathrm{C}-\mathrm{O}$ stretch $\left(1146 \mathrm{~cm}^{-1}\right), \mathrm{C}-\mathrm{O}$ bend $\left(1253 \mathrm{~cm}^{-1}\right), \mathrm{C}-\mathrm{H}$ stretch $\left(2980 \mathrm{~cm}^{-1}\right)$ [43], $\mathrm{CH}_{3}$ and $\mathrm{CH}_{2}$ bends (1392 and $1452 \mathrm{~cm}^{-1}$, respectively). As expected, no band is present in the region of $1645-1630 \mathrm{~cm}^{-1}$ of $\mathrm{C}=\mathrm{C}$ groups in polymer materials, suggesting the complete polymerization of EGDMA. The sulfhydryl ligands MBI and MBT were also characterized by FTIR; however, the characteristic peaks associated with MBI $\left(\mathrm{N}-\mathrm{C}=\mathrm{S}\right.$ stretch $\left(1174 \mathrm{~cm}^{-1}\right)$ and S-H stretch $\left.\left(2877 \mathrm{~cm}^{-1}\right)\right)$ and with MBT (NS-H stretch $\left(2890 \mathrm{~cm}^{-1}\right), \mathrm{N}-\mathrm{C}=\mathrm{S}$ stretch $\left(1082 \mathrm{~cm}^{-1}\right)$ and $\mathrm{C}-\mathrm{S}$ stretch $\left.\left(748-667 \mathrm{~cm}^{-1}\right)\right)$ were not observed $[44,45]$. It should be noted that, the FTIR spectroscopy analysis was not able to provide vibrational information about the ligands in the polymer network because of the small amount of MBI or MBT used in the reaction compared to the cross-linker (EGDMA).

The surface morphology of the synthesized materials was studied by SEM analysis, and the results are shown in Figure 3. In all the cases, rounded particles were obtained, and a slightly higher roughness for the IIP-MBT-AA and NIP-MBT-AA materials was observed. As there were no clear difference among the morphology of the synthesized polymers by SEM analysis, the quantitative measurement of the effective surface area was necessary.

Nitrogen adsorption/desorption analysis was carried out to estimate the pore surface area by $\mathrm{BET}$, and the pore size and total pore volume by Barret-Joyner-Halenda (BJH) analysis. The results are presented in the Table 2, and it can be observed that IIP-MBI-AA presented the largest surface area $\left(11 \mathrm{~m}^{2} \mathrm{~g}^{-1}\right)$ and the smallest pore size $(9.5 \mathrm{~nm})$. This suggests the presence of more imprinted sites for $\mathrm{MeHg}^{+}$and a high adsorption capacity for the IIP-MBI-AA polymer. The IIP-MBT-AA and NIP-MBT-AA materials displayed similar surface areas $\left(5.3\right.$ and $5.5 \mathrm{~m}^{2} \mathrm{~g}^{-1}$, respectively) and pore diameter (11 and $12 \mathrm{~nm}$, respectively), which indicates a small difference on the sorption capacity. Based on this data, IIP-MBI-AA might be considered as a better sorbent than IIP-MBT-AA since the MBI ligand interacts with two hydrogen bonds in the polymer network, creating more binding sites to ensure migration of $\mathrm{MeHg}^{+}$. On the other hand, the MBT ligand only interacts with one hydrogen bond, indicating lower porosity towards binding sites. However, quantitative sorption studies are necessary to corroborate these hypotheses. 

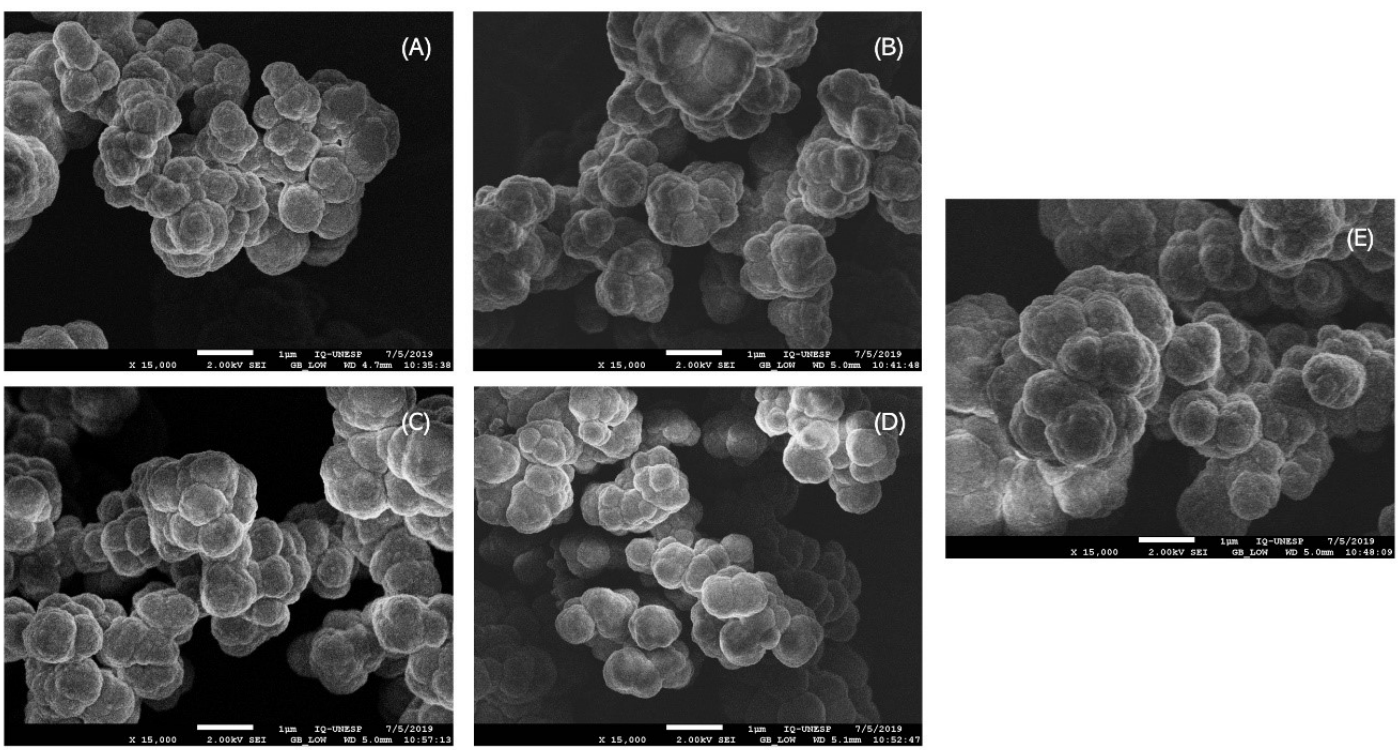

Figure 3. SEM images of (A) IIP-MBI-AA, (B) non-imprinted polymer (NIP)-MBI-AA, (C) IIP-MBT-AA, (D) NIP-MBT-AA, and (E) NIP-AA; the scale bar is $1 \mu \mathrm{m}$ in all figures.

Table 2. Calculated Brunauer-Emmett-Teller (BET) surface area, total pore volume and average pore size.

\begin{tabular}{ccc}
\hline Material & BET Surface Area $/ \mathbf{m}^{\mathbf{2}} \mathbf{g}^{-\mathbf{1}}$ & Pore Size/nm \\
\hline IIP-MBI-AA & 11 & 9.5 \\
NIP-MBI-AA & 6.8 & 21 \\
IIP-MBT-AA & 5.3 & 17 \\
NIP-MBT-AA & 5.5 & 11 \\
NIP-AA & 3.0 & 12 \\
\hline
\end{tabular}

Thermal stability of the polymers was evaluated by TGA and DTA techniques, and the results can be found in Figure S2. All polymers showed similar degradation pattern. The first endothermic event is observed due to the loss of intrinsically bound water at a temperature below $100{ }^{\circ} \mathrm{C}$ in the TGA/DTA curve. This peak is followed by another endothermic peak which is responsible for the main decomposition of the polymers $\left(282-333^{\circ} \mathrm{C}\right)$. It could be that this is attributed to the short chain degradations as well as decarboxylation process, and was continued until $400{ }^{\circ} \mathrm{C}$ [46-48]. Nearly $100 \%$ of total mass of the polymers was decomposed in the range of $282-400^{\circ} \mathrm{C}$. This means that all polymers possess good thermal stability, tolerating temperatures until $282{ }^{\circ} \mathrm{C}$ without significant degradation.

\subsection{Adsorption Studies}

The effect of $\mathrm{pH}$ on $\mathrm{MeHg}^{+}$sorption towards IIPs and NIPs was studied in the $\mathrm{pH}$ range from 2 to 10, and the results are presented in Figure 4A. In all materials, the sorption capacity increased rapidly and reached the maximum capacity at $\mathrm{pH} 8$. For IIP-MBI-AA, the maximum value was $39 \mu \mathrm{g} \mathrm{g}^{-1}$, whereas for NIP-MBI-AA and NIP-AA, the maximum were $30 \mu \mathrm{g} \mathrm{g}^{-1}$ and $17 \mu \mathrm{g} \mathrm{g}^{-1}$, respectively. On the other hand, IIP-MBT-AA $\left(73 \mu \mathrm{g} \mathrm{g}^{-1}\right)$ and NIP-MBT-AA $\left(70 \mu \mathrm{g} \mathrm{g}^{-1}\right)$ display similar adsorption capacity. These results indicate that despite the fact that the IIP-MBI-AA polymer displayed the larger surface area, the IIP-MBT-AA polymer exhibited a highest adsorption capacity. This was probably due to the larger pore size of IIP-MBT-AA which facilitates the analyte sorption. The $\mathrm{pH}$ has a strong influence on $\mathrm{MeHg}^{+}$speciation; for example, a $\mathrm{pH}$ around 6-8 dictates that most of the $\mathrm{MeHg}^{+}$would have a hydroxide group associated with it, while in low $\mathrm{pH} 2-4$, ionic speciation for $\mathrm{MeHg}^{+}$is present. $\mathrm{pH} 8$ was selected to perform all the following experiments because the sorption was more efficient at this $\mathrm{pH}$ value. The same trend was observed in another IIP for $\mathrm{MeHg}^{+}$where the binding capacities increased with high values of $\mathrm{pH}$ [30]. 

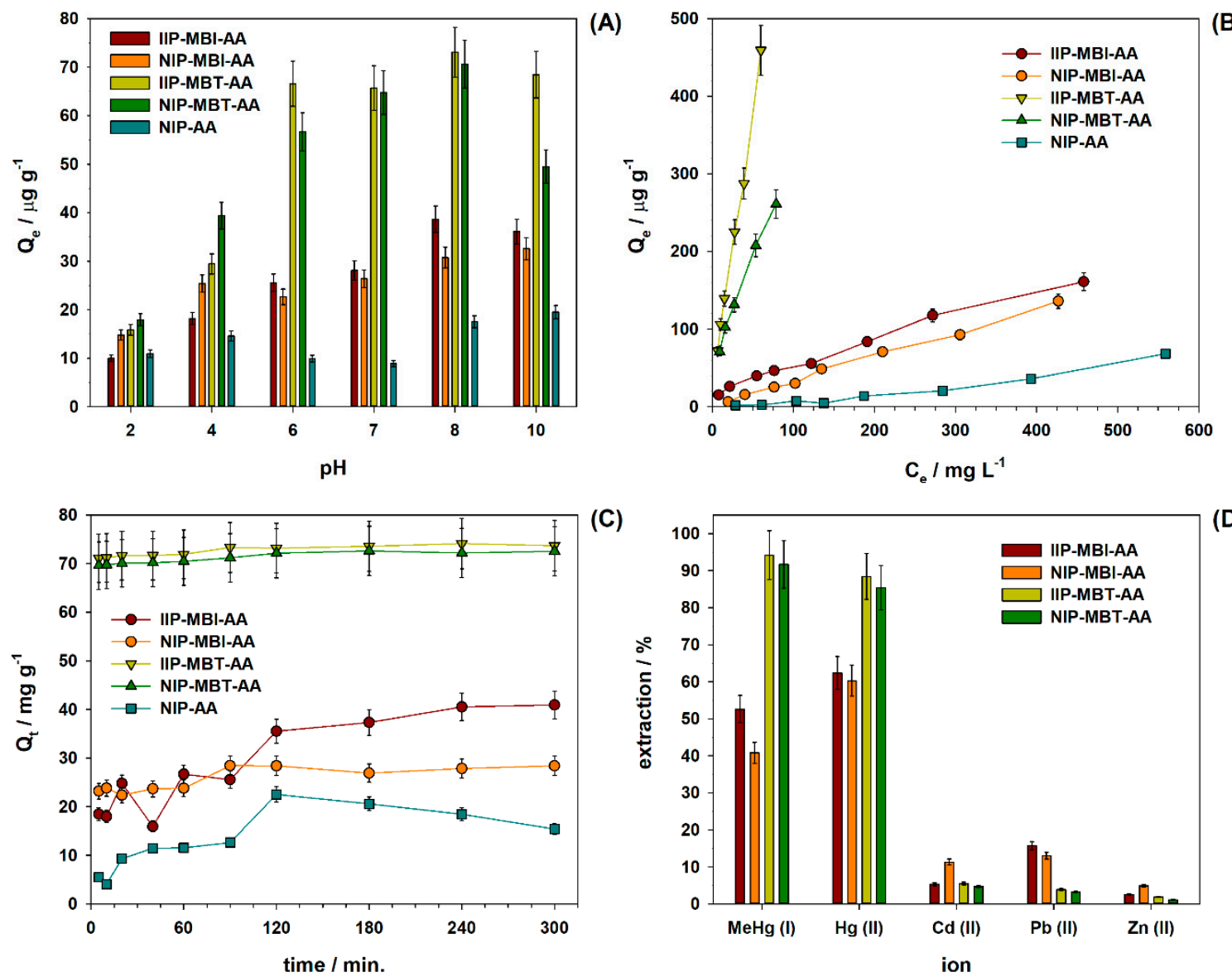

(C)

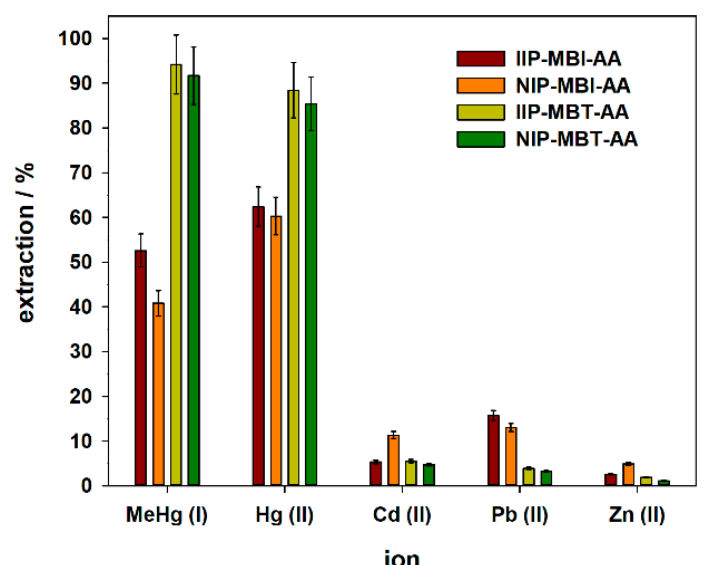

(D)

Figure 4. (A) Effect of $\mathrm{pH}$ on sorption of $\mathrm{MeHg}^{+}$on IIP-MBI-AA, NIP-MBI-AA, IIP-MBT-AA, NIP-MBT-AA, and NIP-AA; $3 \mathrm{mg}$ of polymeric material, $\left[\mathrm{MeHg}^{+}\right]=100 \mu \mathrm{g} \mathrm{L}^{-1}$, volume $=2.0 \mathrm{~mL}$, shaking time $=2 \mathrm{~h}$, room temperature. $(\mathrm{B})$ The effect of $\mathrm{MeHg}^{+}$initial concentration on the adsorption of $\mathrm{MeHg}^{+}$on IIP-MBI-AA, NIP-MBI-AA, IIP-MBT-AA NIP-MBT-AA, and NIP-AA; 3 mg of polymeric material, $\left[\mathrm{MeHg}^{+}\right]=25-800 \mu \mathrm{g} \mathrm{L}^{-1}, \mathrm{pH}=8$, volume $=2.0 \mathrm{~mL}$, shaking time $=2 \mathrm{~h}$, room temperature. (C) Kinetics of $\mathrm{MeHg}^{+}$adsorption on IIP-MBI-AA, NIP-MBI-AA, IIP-MBT-AA NIP-MBT-AA, and NIP-AA; $3 \mathrm{mg}$ of polymeric material, $\left[\mathrm{MeHg}^{+}\right]=100 \mu \mathrm{g} \mathrm{L}^{-1}, \mathrm{pH}=8$, shaking time $=5-300 \mathrm{~min}$, volume $=2.0 \mathrm{~mL}$, room temperature. (D) The selectivity profiles of the IIPs and NIPs for binary mixtures containing $\mathrm{MeHg}^{+}$and potential interferents. In all experiments $n=3$.

Equilibrium data, also known as the adsorption isotherm, are the basic requirement for designing an adsorption system. To evaluate the adsorption capacity, we equilibrated IIPs or NIPs ( $3 \mathrm{mg}$ ) with $\mathrm{MeHg}^{+}$solutions $(2 \mathrm{~mL})$ in the concentration range of $25-600 \mu \mathrm{g} \mathrm{L}^{-1}$ at $\mathrm{pH} 8$ (Figure $4 \mathrm{~B}$ ). The adsorption value increased with the increase in the concentration of $\mathrm{MeHg}^{+}$in all materials, and it revealed that IIP-MBI-AA $\left(161 \mathrm{\mu g} \mathrm{g}^{-1}\right)$ has higher adsorption capacity than that of non-imprinted polymers NIP-MBI $\left(135 \mu \mathrm{g} \mathrm{g}^{-1}\right)$ and NIP-AA $\left(68 \mu \mathrm{g} \mathrm{g}^{-1}\right)$. The significant difference in adsorption capacities indicates the role of ion imprinting in the adsorbent IIP-MBI. In the same way, IIP-MBT-AA $\left(457 \mu \mathrm{g} \mathrm{g}^{-1}\right)$ and NIP-MBT-AA $\left(416 \mu \mathrm{g} \mathrm{g}^{-1}\right)$ display differences in adsorption capacity, as expected.

The data obtained were converted to Langmuir and Freundlich isotherms, and the related constants are given in Table 3. The Langmuir model is represented in a linear equation form as [49]:

$$
\frac{C_{e}}{Q_{e}}=\frac{C_{e}}{Q_{m}}+\frac{1}{b Q_{m}}
$$

where $C_{e}$ is equilibrium concentration of $\mathrm{MeHg}^{+}\left(\mu \mathrm{g} \mathrm{L}^{-1}\right), Q_{e}$ is the adsorption capacity of $\mathrm{MeHg}^{+}$ adsorbed at equilibrium $\left(\mu \mathrm{g} \mathrm{g}^{-1}\right)$ and $Q_{m}$ and $b$ are Langmuir constants, which are related to the 
adsorption capacity and energy of adsorption, respectively. The plot of $C_{e} / Q_{e}$ against $C_{e}$ was used to support the Langmuir isotherm.

Table 3. Langmuir and Freundlich isotherm constants.

\begin{tabular}{|c|c|c|c|c|c|c|}
\hline \multirow{2}{*}{ Material } & \multicolumn{3}{|c|}{ Langmuir } & \multicolumn{3}{|c|}{ Freundlich } \\
\hline & $Q_{m} / \mu g^{-1}$ & $b / \mathrm{L} \mu \mathrm{g}^{-1}$ & $\mathbf{R}^{2}$ & $K_{f / \mu} \mu g^{-1}$ & $n^{-1} / \mathrm{L} \mu g^{-1}$ & $\mathrm{R}^{2}$ \\
\hline IIP-MBI-AA & 217.4 & 0.004 & 0.76 & 4.281 & 0.572 & 0.98 \\
\hline IIP-MBT-AA & 1250 & 0.009 & 0.84 & 13.02 & 0.866 & 0.99 \\
\hline
\end{tabular}

The Freundlich isotherm is an exponential equation that assumes the sorbate concentration increases together with the adsorbent surface [50]. The linear equation used to study the Freundlich isotherm was

$$
\log Q_{e}=\log K_{f}+\frac{1}{n} \log C_{e}
$$

where $K_{f}$ is the intercept showing the sorption capacity of the adsorbents, and $n^{-1}$ is the slope showing the variation of the sorption with the concentration. The results showed that the Freundlich model fitted $\left(R^{2}=0.98-0.99\right)$ better than the Langmuir model $\left(R^{2}=0.76-0.84\right)$ with the experimental behavior of the sorption process. This suggests the interactions and adsorption occur on multiple layers of the sorbents, which is an expected behavior for non-covalently-imprinted polymers.

To study the kinetic of $\mathrm{MeHg}^{+}$sorption onto IIPs and NIPs, batch experiments were carried out. Figure $4 \mathrm{C}$ shows that $\mathrm{MeHg}^{+}$adsorptions reach the maximum capacity after around $120 \mathrm{~min}$ for IIP-MBI-AA, NIP-MBI-AA and NIP-AA, and $95 \mathrm{~min}$ for IIP-MBT-AA and NIP-MBT-AA. The kinetic data were fitted using the pseudo-first-order and pseudo-second-order kinetic models, described by Equations (5) and (6), respectively [35,51].

$$
\begin{gathered}
\log \left(Q_{e}-Q_{t}\right)=\log Q_{e}-\frac{K_{1}}{2.303} \mathrm{t} \\
\frac{\mathrm{t}}{Q_{t}}=\frac{1}{K_{2} Q_{e}^{2}}+\frac{1}{Q_{e}} \mathrm{t}
\end{gathered}
$$

where $Q_{e}\left(\mu \mathrm{g} \mathrm{g}^{-1}\right)$ and $Q_{t}\left(\mu \mathrm{g} \mathrm{g}^{-1}\right)$ are the amounts of adsorbate adsorbed at equilibrium and time $\mathrm{t}$, respectively. $K_{1}\left(\mathrm{~min}^{-1}\right)$ and $K_{2}\left(\mathrm{~g} \mu \mathrm{g}^{-1} \mathrm{~min}^{-1}\right)$ are the pseudo-first-order and pseudo-second-order adsorption rate constants, respectively. The pseudo-first-order and pseudo-second-order kinetic models were used to model the experimental data. From Table 4, we can conclude that the pseudo-second-order kinetic model $\left(\mathrm{R}^{2} \leq 1\right)$ provided a good correlation for the adsorption of $\mathrm{MeHg}^{+}$on IIPs and NIPs compared to the pseudo-first-order $\left(\mathrm{R}^{2}<<1\right)$ kinetic model. Besides, the theoretical values $\left(Q_{\text {the }}\right)$ calculated through the pseudo-second-order model for all polymers were close to the experimental values $\left(Q_{\exp }\right)$.

In order to investigate and to compare the selectivity of IIP-MBI-AA and IIP-MBT-AA for $\mathrm{MeHg}^{+}$, some metal ions $\left(\mathrm{Hg}^{2+}, \mathrm{Cd}^{2+}, \mathrm{Pb}^{2+}\right.$, and $\left.\mathrm{Zn}^{2+}\right)$ were chosen as competitive metals to prepare binary mixtures. The ion $\mathrm{Hg}^{2+}$ was selected as a potential interferent because it often coexists with $\mathrm{MeHg}^{+}$in wastewater and biological samples. The ion $\mathrm{Cd}^{2+}$ was chosen because of its high affinity for thiol groups. The $\mathrm{Pb}^{2+}$ and $\mathrm{Zn}^{2+}$ metal ions were chosen as competitive ions because of their presence in environmental samples. The adsorption capacity $\left(Q\right.$ in $\left.\mu \mathrm{g} \mathrm{g}^{-1}\right)$ and the extraction $(E)$ were calculated using the following equations [52]:

$$
\begin{gathered}
Q=\frac{\left(C_{0}-C_{e}\right)}{m} V, \\
E=\frac{\left(C_{0}-C_{e}\right)}{C_{0}},
\end{gathered}
$$


where $m$ is the mass of polymer $(\mathrm{mg}), V$ is the volume of the solution $(\mathrm{mL})$, and $C_{0}$ and $C_{e}$ are the initial and equilibrium concentrations of $\mathrm{MeHg}^{+}\left(\mu \mathrm{g} \mathrm{L}^{-1}\right)$, respectively. Figure $4 \mathrm{D}$ shows the extraction percentage (obtained by Equation (4)) towards $\mathrm{MeHg}^{+}$and other metal ions. It is evidenced that IIPs and NIPs have selectivity towards mercurial compounds due to sulfhydryl groups in their polymer structures. For $\mathrm{MeHg}^{+}$sorption, the extraction values were $53 \%$ and $41 \%$ for IIP-MBI-AA and NIP-MBI-AA, respectively. However, higher extraction values were obtained $(62 \%$ and $60 \%$ for IIP-MBI-AA and NIP-MBI-AA) for $\mathrm{Hg}^{2+}$ sorption. This suggests that these materials have a higher affinity towards $\mathrm{Hg}^{2+}$ ions than $\mathrm{MeHg}^{+}$ions. Differently, $\mathrm{MeHg}^{+}$extraction values were $94 \%$ and $92 \%$ for IIP-MBT-AA and NIP-MBT-AA, and $\mathrm{Hg}^{2+}$ extraction values were $88 \%$ and $85 \%$ for IIP-MBT-AA and NIP-MBT-AA, respectively.

Table 4. Pseudo-first-order and pseudo-second-order adsorption rate constants.

\begin{tabular}{|c|c|c|c|c|}
\hline \multicolumn{5}{|c|}{ Pseudo-First-Order } \\
\hline Material & $Q_{\text {exp }} / \mu \mathrm{g} \mathrm{g}^{-1}$ & $Q_{\text {the }} \mu \mathrm{g} \mathrm{g}^{-1}$ & $K_{1 / \min ^{-1}} \times 10^{-3}$ & $\mathbf{R}^{2}$ \\
\hline IIP-MBI-AA & 40.93 & 33.23 & 15.43 & 0.886 \\
\hline NIP-MBI-AA & 28.42 & 8.72 & 15.89 & 0.816 \\
\hline NIP-AA & 22.52 & 14.54 & 4.606 & 0.582 \\
\hline IIP-MBT-AA & 74.13 & 2.75 & 7.369 & 0.853 \\
\hline NIP-MBT-AA & 72.62 & 3.40 & 11.28 & 0.916 \\
\hline \multicolumn{5}{|c|}{ Pseudo-Second-Order } \\
\hline Material & $Q_{\exp } / \mu \mathrm{g} \mathrm{g}^{-1}$ & $Q_{\text {the } / \mu g^{-1}}$ & $K_{2} / \mathrm{mg} \mathrm{g}^{-1} \min ^{-1} \times 10^{-3}$ & $\mathbf{R}^{2}$ \\
\hline IIP-MBI-AA & 40.93 & 44.44 & 0.678 & 0.958 \\
\hline NIP-MBI-AA & 28.42 & 28.57 & 7.239 & 0.998 \\
\hline NIP-AA & 22.52 & 18.48 & 2.766 & 0.941 \\
\hline IIP-MBT-AA & 74.13 & 74.07 & 15.85 & 0.999 \\
\hline NIP-MBT-AA & 72.62 & 72.46 & 14.21 & 0.999 \\
\hline
\end{tabular}

Table 3 expresses the distribution coefficient $\left(K_{d}\right)$, the selectivity coefficient $(k)$ and the impression factor (I) values, which could be obtained from the following equations:

$$
\begin{gathered}
K_{d}=\frac{\left(C_{0}-C_{e}\right)}{m C e} V, \\
k=\frac{K_{d}\left(M_{e H g}{ }^{+}\right)}{K_{d}(\text { ion })}, \\
I=\frac{k(I I P)}{k(N I P)},
\end{gathered}
$$

The $K_{d}$ values of IIP-MBI-AA and IIP-MBT-AA for $\mathrm{MeHg}^{+}$were higher compared to those of the respective NIPs. The $k$ for $\mathrm{MeHg}^{+} / \mathrm{Hg}^{2+}, \mathrm{MeHg}^{+} / \mathrm{Cd}^{2+}, \mathrm{MeHg}^{+} / \mathrm{Pb}^{2+}$ and $\mathrm{MeHg} / \mathrm{Zn}^{2+}$ in IIP-MBI-AA were $0.89,20,5.8$ and 35 , respectively. On the other hand, the IIP-MBT-AA $k$ values were 0.86 , 261, 288 and 1510. These results showed that the imprinted polymers retain both species, $\mathrm{Hg}^{2+}$ and $\mathrm{MeHg}^{+}$, with higher binding capacities. IIP-MBT-AA proved higher affinity than IIP-MBI-AA, and it could be because MBT has two sulfhydryl groups, while MBI only has one sulfhydryl group for complexing $\mathrm{MeHg}^{+}$or $\mathrm{Hg}^{2+}$. Taking into consideration the superior extraction efficiency of IIP-MBT-AA, and despite the slightly lower selectivity coefficient, this material was selected for $\mathrm{MeHg}^{+}$sorption in water samples. 


\subsection{Application in Water Samples}

The applicability of the IIP-MBT-AA for preconcentration of trace levels of $\mathrm{MeHg}^{+}$was used as a solid phase adsorbent material. It was tested by spiking and recovery experiments on river water and tap water. The water samples spiked with $\mathrm{MeHg}^{+}$at three different environmentally relevant concentrations $\left(25,50\right.$ and $\left.100 \mu \mathrm{g} \mathrm{L}^{-1}\right)$ were treated with the imprinted polymer. The recoveries obtained were between $84 \%$ and $95 \%$ (Table 5), and the relative standard deviation varied in the range of from 1 to $10 \%$. Recoveries were calculated by the found $\mathrm{MeHg}^{+}$divided per added $\mathrm{MeHg}^{+}$. These results indicate the suitability of the present $\mathrm{MeHg}^{+}$imprinted polymer (IIP-MBT-AA) for the quantitative extraction of $\mathrm{MeHg}^{+}$from natural water samples taking into count the complexity of matrix on the river water sample with recovery percentages slightly lower than tap water.

Table 5. Results obtained in recovery tests using two water samples.

\begin{tabular}{cccc}
\hline Sample & $\mathbf{M e H g}^{+}$Added $/ \boldsymbol{\mu g ~ L}^{-\mathbf{1}}$ & Found in IIP $\mathbf{~} / \boldsymbol{\mu g ~ L}^{-\mathbf{1}}$ & Recovery/\% \\
\hline \multirow{3}{*}{ river water } & 30.1 & $25.5 \pm 0.4$ & 84.8 \\
& 60.4 & $53.7 \pm 0.4$ & 88.8 \\
& 114.5 & $103 \pm 5$ & 89.6 \\
\hline \multirow{3}{*}{ tap water } & 22.4 & $21 \pm 2$ & 93.7 \\
& 58.2 & $55 \pm 2$ & 95.2 \\
& 113.5 & $101 \pm 2$ & 88.5 \\
\hline
\end{tabular}

a Standard deviation for $n=3$.

\section{Conclusions}

The computational simulation based on DFT and experimental validations proved to be a powerful tool to design a $\mathrm{MeHg}^{+}$IIP. The theoretical studies showed that MBI, MBT, AA and EtOH were suitable components for the MeHg-IIP synthesis. The performances of the IIP-MBI-AA and IIP-MBT-AA polymers were compared. The effect of $\mathrm{pH}$ and adsorption isotherm of imprinted and control polymers revealed differences at $\mathrm{pH}=8$ with a superior maximum adsorption capacity for the IIP-MBT-AA material. The adsorption isotherm studies indicated that the Freundlich isotherm fitted well the adsorption of $\mathrm{MeHg}^{+}$on the imprinted and control polymers. Additionally, the kinetic study showed follow the pseudo-second-order kinetic equation well in the adsorption process. The selectivity studies showed that the selectivity coefficient $k$ values for IIP-MBT-AA were $\mathrm{MeHg}^{+} / \mathrm{Hg}^{2+}(0.86)$, $\mathrm{MeHg}^{+} / \mathrm{Cd}^{2+}(261), \mathrm{MeHg}^{+} / \mathrm{Pb}^{2+}(288)$ and $\mathrm{MeHg}^{+} / \mathrm{Zn}^{2+}$ (1510), revealing that mercurial compounds have high affinity for the recognition sites. The IIP-MBT-AA was successfully applied to concentrate $\mathrm{MeHg}^{+}$ions in water samples with satisfactory results.

Supplementary Materials: The following are available online at http://www.mdpi.com/2079-4991/10/12/2541/s1, Figure S1: FTIR spectra of (A) MBI, IIP-MBI-AA, NIP-MBI-AA, and NIP-AA; and (B) MBT, IIP-MBT-AA, NIP-MBT-AA, and NIP-AA. Figure S2: TGA analysis of IIP-MBI-AA, NIP-MBI-AA, IIP-MBT-A, NIP-MBT-AA and NIP-AA. Table S1: Comparative selected bond lengths $(\AA)$ for $\mathrm{MeHg}^{+}-\mathrm{MBI}$ and $\mathrm{MeHg}^{+}-\mathrm{MBT}$. Table S2: Predicted binding energy of $\mathrm{MeHg}^{+}-\mathrm{MBI}$ and $\mathrm{MeHg}^{+}-\mathrm{MBT}$ with FMs. Table S3: Selectivity parameters for the adsorption of $\mathrm{Hg}^{2+}, \mathrm{Zn}^{2+}, \mathrm{Cd}^{2+}$ and $\mathrm{Pb}^{2+}$ ions with respect to $\mathrm{MeHg}^{+}$.

Author Contributions: Conceptualization, R.L.M.M., M.D.P.T.S. and G.P.; methodology, R.L.M.M., J.E.L.V., S.K., R.R.A.P. and M.A.M.; formal analysis, R.L.M.M. and J.E.L.V.; investigation, R.L.M.M., J.E.L.V., S.K., R.R.A.P. and M.A.M.; resources, M.D.P.T.S.; data curation, R.L.M.M., J.E.L.V., R.R.A.P. and M.A.M.; writing-original draft preparation, R.L.M.M., J.E.L.V., S.K., R.R.A.P. and M.A.M.; writing-review and editing, R.L.M.M., J.E.L.V. and L.M.G.; supervision, M.D.P.T.S.; project administration, M.D.P.T.S.; funding acquisition, M.D.P.T.S. and G.P. All authors have read and agreed to the published version of the manuscript.

Funding: This research was funded by Fondo Nacional de Desarrollo Científico y Tecnológico (FONDECYT), grants number 227-2018, 023-2019, and 237-2015-FONDECYT, by Conselho Nacional de Desenvolvimento Científico e Tecnológico (CNPq), grants number 301728/2019-4, 408050/2018-7, and 465571/2014-0, by Fundação de Amparo à Pesquisa do Estado de São Paulo (FAPESP), grants number 2014/50945-4, 2017/24198-2, 2018/14425-7, and 2019/00677-7, and by Coordenação de Aperfeiçoamento de Pessoal de Nível Superior (CAPES), grant number 001. 
Acknowledgments: All the computational studies were conducted using resources and facilities provided by the Center for Scientific Computing (NCC/GridUNESP) of São Paulo State University (UNESP). The authors would like to thank Lucas Neres and Raquel Fernanda Milani for their valuable help with theoretical calculations and $\mathrm{MeHg}^{+}$determination.

Conflicts of Interest: The authors declare no conflict of interest.

\section{References}

1. Wiener, J.; Krabbenhoft, D.; Heinz, G.; Scheuhammer, A. Ecotoxicology of mercury. In Handbook of Ecotoxicology, 2nd ed.; CRC Press: Boca Raton, FL, USA, 2002.

2. Hong, Y.-S.; Kim, Y.-M.; Lee, K.-E. Methylmercury exposure and health effects. J. Prev. Med. Public Health 2012, 45, 353-363. [CrossRef] [PubMed]

3. Steuerwald, U.; Weihe, P.; Jørgensen, P.J.; Bjerve, K.; Brock, J.; Heinzow, B.; Budtz-Jørgensen, E.; Grandjean, P. Maternal seafood diet, methylmercury exposure, and neonatal neurologic function. J. Pediatr. 2000, 136, 599-605. [CrossRef]

4. $\quad$ Chen, C.Y.; Serrell, N.; Evers, D.C.; Fleishman, B.J.; Lambert, K.F.; Weiss, J.; Mason, R.P.; Bank, M.S. Meeting report: Methylmercury in marine ecosystems-From sources to seafood consumers. Environ. Health Perspect. 2008, 116, 1706-1712. [CrossRef] [PubMed]

5. Guimaraes, J.R.D.; Betancourt, O.; Miranda, M.R.; Barriga, R.; Cueva, E.; Betancourt, S. Long-range effect of cyanide on mercury methylation in a gold mining area in southern Ecuador. Sci. Total Environ. 2011, 409, 5026-5033. [CrossRef] [PubMed]

6. Lino, A.S.; Kasper, D.; Guida, Y.S.; Thomaz, J.R.; Malm, O. Total and methyl mercury distribution in water, sediment, plankton and fish along the Tapajós River basin in the Brazilian Amazon. Chemosphere 2019, 235, 690-700. [CrossRef]

7. Vacchina, V.; Séby, F.; Chekri, R.; Verdeil, J.; Dumont, J.; Hulin, M.; Sirot, V.; Volatier, J.-L.; Serreau, R.; Rousseau, A.; et al. Optimization and validation of the methods for the total mercury and methylmercury determination in breast milk. Talanta 2017, 167, 404-410. [CrossRef]

8. Covaci, E.; Senila, M.; Ponta, M.; Darvasi, E.; Petreus, D.; Frentiu, M.; Frentiu, T. Methylmercury determination in seafood by photochemical vapor generation capacitively coupled plasma microtorch optical emission spectrometry. Talanta 2017, 170, 464-472. [CrossRef]

9. Qin, C.; Chen, M.; Yan, H.; Shang, L.; Yao, H.; Li, P.; Feng, X. Compound specific stable isotope determination of methylmercury in contaminated soil. Sci. Total Environ. 2018, 644, 406-412. [CrossRef]

10. de Paiva, E.L.; Milani, R.F.; Boer, B.S.; Quintaes, K.D.; Morgano, M.A. Methylmercury in fish species used in preparing sashimi: A case study in Brazil. Food Control 2017, 80, 104-112. [CrossRef]

11. Huang, Y.; Tang, J.; Gai, L.; Gong, Y.; Guan, H.; He, R.; Lyu, H. Different approaches for preparing a novel thiol-functionalized graphene oxide/Fe-Mn and its application for aqueous methylmercury removal. Chem. Eng. J. 2017, 319, 229-239. [CrossRef]

12. Wang, L.; Hou, D.; Cao, Y.; Ok, Y.S.; Tack, F.M.G.; Rinklebe, J.; O'Connor, D. Remediation of mercury contaminated soil, water, and air: A review of emerging materials and innovative technologies. Environ. Int. 2020, 134, 105281. [CrossRef]

13. Fu, X.-C.; Wu, J.; Nie, L.; Xie, C.-G.; Liu, J.-H.; Huang, X.-J. Electropolymerized surface ion imprinting films on a gold nanoparticles/single-wall carbon nanotube nanohybrids modified glassy carbon electrode for electrochemical detection of trace mercury(II) in water. Anal. Chim. Acta 2012, 720, 29-37. [CrossRef]

14. Speltini, A.; Scalabrini, A.; Maraschi, F.; Sturini, M.; Profumo, A. Newest applications of molecularly imprinted polymers for extraction of contaminants from environmental and food matrices: A review. Anal. Chim. Acta 2017, 974, 1-26. [CrossRef]

15. Benachio, I.; Lobato, A.; Gonçalves, L.M. Employing molecularly imprinted polymers in the development of electroanalytical methodologies for antibiotic determination. J. Mol. Recognit. 2020. [CrossRef] [PubMed]

16. Gonçalves, L.M. Electropolymerized molecularly imprinted polymers: Perceptions based on recent literature for soon-to-be world-class scientists. Curr. Opin. Electrochem. 2021, 25, 100640. [CrossRef]

17. Zhou, Z.; Kong, D.; Zhu, H.; Wang, N.; Wang, Z.; Wang, Q.; Liu, W.; Li, Q.; Zhang, W.; Ren, Z. Preparation and adsorption characteristics of an ion-imprinted polymer for fast removal of $\mathrm{Ni}$ (II) ions from aqueous solution. J. Hazard. Mater. 2018, 341, 355-364. [CrossRef] [PubMed] 
18. Dahaghin, Z.; Mousavi, H.Z.; Sajjadi, S.M. A novel magnetic ion imprinted polymer as a selective magnetic solid phase for separation of trace lead(II) ions from agricultural products, and optimization using a Box-Behnken design. Food Chem. 2017, 237, 275-281. [CrossRef]

19. Dahaghin, Z.; Kilmartin, P.A.; Mousavi, H.Z. Novel ion imprinted polymer electrochemical sensor for the selective detection of lead(II). Food Chem. 2020, 303, 125374. [CrossRef]

20. R. Ganjali, M.; Alizadeh, T.; Larijani, B.; Aghazadeh, M.; Pourbasheer, E.; Norouzi, P. Biomimetic electrochemical sensors based on imprinted polymers for determination of mercury ion. Curr. Anal. Chem. 2016, 13, 62-69. [CrossRef]

21. Jakavula, S.; Biata, N.R.; Dimpe, K.M.; Pakade, V.E.; Nomngongo, P.N. A critical review on the synthesis and application of ion-imprinted polymers for selective preconcentration, speciation, removal and determination of trace and essential metals from different matrices. Crit. Rev. Anal. Chem. 2020, 1-13. [CrossRef]

22. Branger, C.; Meouche, W.; Margaillan, A. Recent advances on ion-imprinted polymers. React. Funct. Polym. 2013, 73, 859-875. [CrossRef]

23. Biju, V.; Gladis, J.M.; Rao, T.P. Ion imprinted polymer particles: Synthesis, characterization and dysprosium ion uptake properties suitable for analytical applications. Anal. Chim. Acta 2003, 478, 43-51. [CrossRef]

24. Jinadasa, K.K.; Peña-Vázquez, E.; Bermejo-Barrera, P.; Moreda-Piñeiro, A. New adsorbents based on imprinted polymers and composite nanomaterials for arsenic and mercury screening/speciation: A review. Microchem. J. 2020, 156, 104886. [CrossRef]

25. Khodadadian, M.; Ahmadi, F. Computer-assisted design and synthesis of molecularly imprinted polymers for selective extraction of acetazolamide from human plasma prior to its voltammetric determination. Talanta 2010, 81, 1446-1453. [CrossRef]

26. Jiang, W.; Chen, Z.; Cheng, X.; Wu, W.; Wu, Y.; Xu, L.; Fu, F. A novel ion imprinted SiO 2 microsphere for the specific and rapid extraction and pre-concentration of ultra-trace methyl mercury. RSC Adv. 2016, 6, 40100-40105. [CrossRef]

27. Jiang, W.; Jin, X.; Yu, X.; Wu, W.; Xu, L.; Fu, F. Ion-imprinted magnetic nanoparticles for specific separation and concentration of ultra-trace methyl mercury from aqueous sample. J. Chromatogr. A 2017, 1496, 167-173. [CrossRef] [PubMed]

28. Yordanova, T.; Dakova, I.; Balashev, K.; Karadjova, I. Polymeric ion-imprinted nanoparticles for mercury speciation in surface waters. Microchem. J. 2014, 113, 42-47. [CrossRef]

29. Rodríguez-Reino, M.P.; Rodríguez-Fernández, R.; Peña-Vázquez, E.; Domínguez-González, R.; Bermejo-Barrera, P.; Moreda-Piñeiro, A. Mercury speciation in seawater by liquid chromatography-inductively coupled plasma-mass spectrometry following solid phase extraction pre-concentration by using an ionic imprinted polymer based on methyl-mercury-phenobarbital interaction. J. Chromatogr. A 2015, 1391, 9-17. [CrossRef] [PubMed]

30. Rodríguez-Fernández, R.; Peña-Vázquez, E.; Bermejo-Barrera, P. Synthesis of an imprinted polymer for the determination of methylmercury in marine products. Talanta 2015, 144, 636-641. [CrossRef]

31. Jinadasa, K.K.; Herbello-Hermelo, P.; Peña-Vázquez, E.; Bermejo-Barrera, P.; Moreda-Piñeiro, A. Mercury speciation in edible seaweed by liquid chromatography-Inductively coupled plasma mass spectrometry after ionic imprinted polymer-solid phase extraction. Talanta 2020, 121841. [CrossRef]

32. De Barros, L.A.; Pereira, L.A.; Custódio, R.; Rath, S. A novel computational approach for development of highly selective fenitrothion imprinted polymer: Theoretical predictions and experimental validations. J. Braz. Chem. Soc. 2014, 25, 619-628. [CrossRef]

33. Couto, R.A.S.; Costa, S.S.; Mounssef, B.; Pacheco, J.G.; Fernandes, E.; Carvalho, F.; Rodrigues, C.M.P.; Delerue-Matos, C.; Braga, A.A.C.; Gonçalves, L.M.; et al. Electrochemical sensing of ecstasy with electropolymerized molecularly imprinted poly(o-phenylenediamine) polymer on the surface of disposable screen-printed carbon electrodes. Sens. Actuators B Chem. 2019, 290, 378-386. [CrossRef]

34. Couto, R.A.S.; Mounssef, B.; Carvalho, F.; Rodrigues, C.M.P.; Braga, A.A.C.; Aldous, L.; Gonçalves, L.M.; Quinaz, M.B. Methylone screening with electropolymerized molecularly imprinted polymer on screen-printed electrodes. Sens. Actuators B Chem. 2020, 316, 128133. [CrossRef]

35. Khan, S.; Hussain, S.; Wong, A.; Foguel, M.V.; Gonçalves, L.M.; Pividori Gurgo, M.I.; Taboada Sotomayor, M.d.P. Synthesis and characterization of magnetic-molecularly imprinted polymers for the HPLC-UV analysis of ametryn. React. Funct. Polym. 2018, 122, 175-182. [CrossRef]

36. Frisch, M.J.; Trucks, G.W.; Schlegel, H.B.; Scuseria, G.E.; Robb, M.A.; Cheeseman, J.R.; Scalmani, G.; Barone, V.; Mennucci, B.; Petersson, G.A.; et al. Gaussian 09; Revision D.01; Gaussian, Inc: Wallingford, CT, USA, 2009. 
37. Singh, I.; El-Emam, A.A.; Pathak, S.K.; Srivastava, R.; Shukla, V.K.; Prasad, O.; Sinha, L. Experimental and theoretical DFT (B3LYP, X3LYP, CAM-B3LYP and M06-2X) study on electronic structure, spectral features, hydrogen bonding and solvent effects of 4-methylthiadiazole-5-carboxylic acid. Mol. Simul. 2019, 45, 1029-1043. [CrossRef]

38. Hehre, W.J.; Ditchfield, R.; Pople, J.A. Self-consistent molecular orbital methods. XII. Further extensions of Gaussian-type basis sets for use in molecular orbital studies of organic molecules. J. Chem. Phys. 1972, 56, 2257-2261. [CrossRef]

39. Francl, M.M.; Pietro, W.J.; Hehre, W.J.; Binkley, J.S.; Gordon, M.S.; DeFrees, D.J.; Pople, J.A. Self-consistent molecular orbital methods. XXIII. A polarization-type basis set for second-row elements. J. Chem. Phys. 1982, 77, 3654-3665. [CrossRef]

40. Hay, P.J.; Wadt, W.R. Ab initio effective core potentials for molecular calculations. Potentials for the transition metal atoms Sc to Hg. J. Chem. Phys. 1985, 82, 270-283. [CrossRef]

41. Rabenstein, D.L. The aqueous solution chemistry of methylmercury and its complexes. Acc. Chem. Res. 1978, 11, 100-107. [CrossRef]

42. Bravo, J.; Casas, J.S.; Castano, M.V.; Gayoso, M.; Mascarenhas, Y.P.; Sanchez, A.; Santos, C.d.O.P.; Sordo, J. Methyl- and phenylmercury(II) derivatives of 2-mercaptobenzothiazole. Crystal structure of (2-benzothiazolylthio)methylmercury(II). Inorg. Chem. 1985, 24, 3435-3438. [CrossRef]

43. Fu, X.-C.; Chen, X.; Guo, Z.; Xie, C.-G.; Kong, L.-T.; Liu, J.-H.; Huang, X.-J. Stripping voltammetric detection of mercury(II) based on a surface ion imprinting strategy in electropolymerized microporous poly(2-mercaptobenzothiazole) films modified glassy carbon electrode. Anal. Chim. Acta 2011, 685, 21-28. [CrossRef] [PubMed]

44. Doneux, T.; Buess-Herman, C.; Lipkowski, J. Electrochemical and FTIR characterization of the self-assembled monolayer of 2-mercaptobenzimidazole on Au(111). J. Electroanal. Chem. 2004, 564, 65-75. [CrossRef]

45. Bigotto, A. Vibrational spectra of benzimidazol-2-thione. Spectrosc. Lett. 1991, 24, 69-80. [CrossRef]

46. Luliński, P.; Kalny, P.; Giebułtowicz, J.; Maciejewska, D.; Wroczyński, P. Synthesis and characterization of cadmium(II)-imprinted poly(1-allyl-2-thiourea-co-ethylene glycol dimethacrylate) particles for selective separation. Polym. Bull. 2014, 71, 1727-1741. [CrossRef]

47. Woźnica, M.; Luliński, P. Design of selective molecularly imprinted sorbent for the optimized solid-phase extraction of S-pramipexole from the model multicomponent sample of human urine. J. Sep. Sci. 2019, 42, 1412-1422. [CrossRef]

48. Marć, M.; Wieczorek, P.P. The preparation and evaluation of core-shell magnetic dummy-template molecularly imprinted polymers for preliminary recognition of the low-mass polybrominated diphenyl ethers from aqueous solutions. Sci. Total Environ. 2020, 724, 138151. [CrossRef]

49. Magalhães, P.J.; Vieira, J.S.; Gonçalves, L.M.; Pacheco, J.G.; Guido, L.F.; Barros, A.A. Isolation of phenolic compounds from hop extracts using polyvinylpolypyrrolidone: Characterization by high-performance liquid chromatography-diode array detection-electrospray tandem mass spectrometry. J. Chromatogr. A 2010, 1217, 3258-3268. [CrossRef]

50. Khairi, N.; Yusof, N.; Abdullah, A.; Mohammad, F. Removal of toxic mercury from petroleum oil by newly synthesized molecularly-imprinted polymer. Int. J. Mol. Sci. 2015, 16, 10562-10577. [CrossRef]

51. Adauto, A.; Khan, S.; Augusto da Silva, M.; Gomes Neto, J.A.; Picasso, G.; Sotomayor, M.d.P.T. Synthesis, characterization and application of a novel ion hybrid imprinted polymer to adsorb $\mathrm{Cd}(\mathrm{II})$ in different samples. Environ. Res. 2020, 187, 109669. [CrossRef]

52. Luna Quinto, M.; Khan, S.; Picasso, G.; Taboada Sotomayor, M.D.P. Synthesis, characterization, and evaluation of a selective molecularly imprinted polymer for quantification of the textile dye acid violet 19 in real water samples. J. Hazard. Mater. 2020, 384, 121374. [CrossRef]

Publisher's Note: MDPI stays neutral with regard to jurisdictional claims in published maps and institutional affiliations. 